\author{
Gregory A. Eschenauer \\ Simon W. Lam
}

\section{Supratherapeutic oseltamivir levels during continuous dialysis: an expected risk}

Accepted: 30 August 2010

Published online: 20 November 2010

(C) Copyright jointly held by Springer and ESICM 2010

Dear Editor,

We read with interest the recent correspondence by Lemaitre and colleagues. The authors describe the case of a patient treated with highdose oseltamivir (150 mg BID) for severe infection due to influenza A/H1N1. Despite receiving simultaneous extracorporeal membrane oxygenation (ECMO) and continuous veno-venous hemodiafiltration (CVVHDF), oseltamivir carboxylate (OC) $C_{\max }$ and $\mathrm{AUC}_{0-12}$ were fivefold higher in comparison to data from healthy volunteers [1]. We offer a possible explanation for their findings.

After oral administration, oseltamivir phosphate (an inactive prodrug) is rapidly converted to $\mathrm{OC}$, the active metabolite. OC is primarily (60-70\%) eliminated renally as unchanged drug through a combination of glomerular filtration and tubular secretion. The mean total renal clearance of $\mathrm{OC}$ in healthy volunteers is $18.8 \mathrm{~L} / \mathrm{h}$. This vastly exceeds glomerular filtration rate $(\sim 125 \mathrm{ml} / \mathrm{min}=7.5 \mathrm{~L} / \mathrm{h})$, which suggests a significant degree of clearance via tubular secretion. Indeed, tubular secretion of OC occurs via the anionic transport process and inhibition of secretion by probenecid results in an approximate twofold increase in $C_{\max }, 2.5$-fold increase in AUC, and a 50\% decrease in renal clearance [2].

OC is readily dialyzable through continuous renal replacement therapy (CRRT). The effects of continuous veno-venous hemofiltration (CVVHF) on the clearance of OC were investigated in an in vitro study. The authors found a minimal amount of adsorption to the hemofilters $(\sim 1 \%)$ and a sieving coefficient of $\sim 1$ [3]. This would suggest that clearance during hemodiafiltration should approximate the sum of dialysate and ultrafiltrate flow rates [4]. In the case by Lemaitre and colleagues, the patient was initiated on CVVHDF with flow rates of $1.5 \mathrm{~L} / \mathrm{h}$ dialysate and $1.5 \mathrm{~L} / \mathrm{h}$ ultrafiltration. We assume that there was minimal tubular secretion of drug since the patient was anuric. Therefore, the maximum extracorporeal clearance rate generated by CVVHDF would be $3 \mathrm{~L} / \mathrm{h}$. Although Lemaitre and colleagues point out that adhesion of drugs to the ECMO circuit may occur, it is unlikely that this would significantly contribute to the overall drug clearance [5]. Given the above data, the clearance of OC in this patient would be expected to be $\sim 6$ times lower than that in healthy volunteers $(3 \mathrm{~L} / \mathrm{h}$ vs. $18.8 \mathrm{~L} / \mathrm{h})$, which is in line with their findings.

Oseltamivir is well-tolerated to doses up to $1,000 \mathrm{mg}$, with the main adverse effect being transient gastrointestinal upset [2]. Understandably, many clinicians prefer to dose oseltamivir aggressively when treating critically ill patients with influenza (especially that due to H1N1). Given the paucity of data, it is difficult to make firm dosing recommendations at this time. However, investigators and clinicians should be aware that supratherapeutic levels should be expected when high-dose oseltamivir is given to patients receiving CRRT.

\section{References}

1. Lemaitre F, Luyt CE, Roullet-Renoleau F, Nieszkowska A, Zahr N, Fernandez C, Farinotti R, Combes A (2010)

Oseltamivir carboxylate accumulation in a patient treated by haemodiafiltration and extracorporeal membrane oxygenation. Intensive Care Med 36:1273-1274

2. He G, Massarella J, Ward P (1999) Clinical pharmacokinetics of the prodrug oseltamivir and its active metabolite Ro 64-0802. Clin Pharmacokinet 37:471-484

3. Gruber PC, Tian Q, Gomersall CD, Joynt GM, Choi GY (2007) An in vitro study of the elimination of oseltamivir carboxylate by haemofiltration. Int $\mathrm{J}$ Antimicrob Agents 30:95-97

4. Choi G, Gomersall CD, Tian Q, Joynt GM, Freebairn R, Lipman J (2009) Principles of antibacterial dosing in continuous renal replacement therapy. Crit Care Med 37:2268-2282

5. Buck ML (2003) Pharmacokinetic changes during extracorporeal membrane oxygenation: implications for drug therapy of neonates. Clin Pharmacokinet $42: 403-417$

\section{G. A. Eschenauer}

Department of Pharmacy, University of Pittsburgh Medical Center, Falk Medical Building, Suite 3A, 3601 Fifth Avenue, Pittsburgh, PA 15213, USA

\section{S. W. Lam $(\bowtie)$}

Department of Pharmacy,

Cleveland Clinic Health System, 9500 Euclid Avenue Mail Code: JJN1-02, Cleveland, OH 44195, USA

e-mail: lams@ccf.org

Tel.: +1-216-4448913

Fax: +1-216-4448837 